\title{
Indications and results in anophthalmic socket reconstruction using dermis-fat graft
}

\author{
This article was published in the following Dove Press journal: \\ Clinical Ophthalmology \\ 4 May 2015 \\ Number of times this article has been viewed
}

\section{Orapan Aryasit \\ Passorn Preechawai}

Department of Ophthalmology, Faculty of Medicine, Prince of Songkla University, Hat Yai, Songkhla, Thailand
Correspondence: Orapan Aryasit Department of Ophthalmology, Faculty of Medicine, Prince of Songkla University, Kanjanavanit Road, Hat Yai, Songkhla 90II0, Thailand

Email all_or_none2278I@hotmail.com
Objectives: To present the indications for a dermis-fat graft in anophthalmic socket reconstruction and evaluate the results of this procedure.

Design: Retrospective review, interventional case series.

Methods: In our study, there were 41 patients who received either primary or secondary dermisfat graft between August 1, 2007 and July 31, 2012 at Songklanagarind Hospital.

Results: The type of dermis-fat graft used in our study consisted of both primary dermis-fat grafts (6/41) and secondary dermis-fat grafts (35/41). The major indications for dermis-fat graft were exposure (13/41), extrusion (11/41), and volume insufficiency with a shallow fornix (10/41), which accounted for $82.9 \%$ of the total cases. A total of 30 patients were able to wear the eye prosthesis over a mean follow-up time of $32.3 \pm 19.0$ months. The success rate of the dermis-fat graft alone was $73.3 \%$, while that of the simultaneous dermis-fat graft and mucousmembrane graft was $25 \%$.

Conclusion: The most common indications for a dermis-fat graft were extrusion and large exposure. Dermis-fat graft is an alternative implant type in complicated enucleation/evisceration patients, which has a good success rate.

Keywords: dermis-fat graft, anophthalmic socket, extrusion, exposure

\section{Introduction}

Enucleation and evisceration introduce the anophthalmic socket syndrome, which consists of enophthalmos due to orbital tissue shrinkage, deep superior sulcus, and shallow fornix and affects the cosmesis acceptance. ${ }^{1}$ Therefore, an ideal anophthalmic socket leads to a good result in terms of the best eye prosthesis. The anophthalmic socket has been associated with many complications such as discharge, entropion, ectropion, exposure or extrusion of the orbital implant, infection, migration of the orbital implant, contracted socket, and ptosis. ${ }^{2}$ The dermis-fat graft is a treatment option for anophthalmic socket reconstruction, especially in patients with exposure or extrusion of the orbital implant. ${ }^{3}$ The advantage of dermis-fat graft consists of its ability to replace the orbital volume and surface of the anophthalmic socket; moreover, it has never been exposed and extruded. The dermis-fat graft can be used in cases of volume insufficiency in retinoblastoma eyes by means of volume augmentation. ${ }^{4}$ Some children with an anophthalmic socket have undergone autologous dermis-fat grafts with good results. ${ }^{5}$ However, this procedure's disadvantages are a second site of surgical wound and dermis-fat graft shrinkage.

The dermis-fat graft has been used as an orbital implant in primary enucleation, secondary implants, and tissue augmentation in a contracted socket. ${ }^{3,6-9}$ In developed countries, most surgeons prefer to use a porous polyethylene implant. ${ }^{10,11}$ On the other hand, in Thailand, surgeons use both nonporous and porous orbital implants in 
enucleation and evisceration. Regarding implant exposure, surgical management depends on the defect size, type of orbital implant, and duration of orbital implant exposure. ${ }^{12}$ The exposure size should be less than $3 \mathrm{~mm}$, and the observation may be adequate. In case of larger exposures, the use of a Müller muscle flap and tarsal patch-flap is recommended. ${ }^{13-15}$ However, when the defect size is very large, surgeons usually perform a dermis-fat graft for anophthalmic socket reconstruction. ${ }^{16,17}$

\section{Materials and methods}

This is a retrospective interventional case series containing data collected between August 1, 2007 and July 31, 2012. Institutional review board/ethics committee approval was obtained at Songklanagarind Hospital, and this study adhered to the tenets of the Declaration of Helsinki.

We included patients who underwent either primary or secondary dermis-fat grafts for the first time. We reviewed the medical records of these patients to obtain the following data: demographics, duration of symptoms, indications for the dermis-fat graft, and postoperative conditions for eye prosthesis wear and cosmesis. The patient satisfaction (obtained via interviews) with the cosmetic result was classified as good, fair, or poor. Experienced surgeons performed the graft on 24 cases and inexperienced ones on 17 cases.

The surgical technique employed in our study is a very simple procedure. After informed consents were obtained, all patients underwent the dermis-fat graft under general anesthesia. A 1:1 mixture of 1\% lidocaine (1:100,000 epinephrine) with $0.5 \%$ bupivacaine was administered via a retrobulbar injection. We prepared the raw surface for the dermis-fat graft and measured it in three dimensions (width, length, and depth). Adding 30\% to the measurement of the defect, an incision was performed on the patient's buttock where dermis-fat tissue was dissected and skin for the dermisfat graft removed. The dermis-fat graft was then placed in the prepared socket; a single interrupted 6-0 polyglactin suture was performed between the dermis-fat graft and the conjunctiva-Tenon complex. This was followed by the placement of the conformer and temporary tarsorrhaphy.

All of the four patients who underwent the combined procedure (dermis-fat graft with mucous-membrane graft) had an inadequate fornix, intraoperatively following the dermis-fat graft. Therefore, a mucous membrane was added to deepen the fornix, and the size of the defect was measured. The mucosal surface of the lip was marked and injected by a $1: 1$ mixture of $1 \%$ lidocaine (1:100,000 epinephrine) with $0.5 \%$ bupivacaine. The lip was retracted with two towel clamps and incised with a number-15 blade. The mucosal graft was dissected and defatted as thin as possible using Westcott scissors. The graft was sutured into the defect of the fornix using interrupted and continuous-running 6-0 polyglactin sutures. The fornix was sutured in place with 2-3 double-arm 4-0 polyglactin sutures. This was followed by the placement of the conformer and temporary tarsorrhaphy.

For the patients who underwent a dermis-fat graft but could not wear the eye prosthesis well because of a contracted socket, we added a mucous-membrane graft to deepen the fornix. The palpebral conjunctiva was injected by a $1: 1$ mixture of $1 \%$ lidocaine (1:100,000 epinephrine) with $0.5 \%$ bupivacaine and incised using monopolar cautery. Then we dissected and lysed the scar to create space, especially in the inferior fornix. The mucous-membrane graft was prepared and sutured with interrupted and continuous-running 6-0 polyglactin sutures. This was followed by the placement of the conformer and temporary tarsorrhaphy.

\section{Results}

Forty-one patients underwent dermis-fat grafts; it was a primary procedure in six patients and a secondary one in 35 others. Our study comprised 23 males and 18 females, with a mean age of $40.38( \pm 25.64)$ years. The mean follow-up time was $32.2 \pm 19.0$ months. The median duration between the date of visit and the date of secondary dermis-fat graft surgery was 7.1 months (range 1 day-38.2 months).

The commonest (13 cases) clinical presentation to indicate the dermis-fat graft was an exposed implant (mean width of $7.6 \mathrm{~mm}$; range $5.0-10.0 \mathrm{~mm}$ ); 10 of these cases involved infection. Discharge samples from four infected exposure-related implants were sent for culture. The results confirmed infection by coagulase-negative Staphylococcus in two cases and Pseudomonas aeruginosa in one case, and the culture for the other one resulted in no growth. Three of the 13 exposed implants underwent defect-closure intervention by means of an amniotic membrane graft (two) and tarsoconjunctival graft (one) before the secondary dermis-fat graft. The second most common condition was extrusion. Eleven patients received dermis-fat grafts due to enucleation/ evisceration related to trauma (data shown in Table 1), which consisted of four blast injuries (one primary dermis-fat graft, three severe globe distortions), four severe penetrating injuries (one primary enucleation with nonporous implant, three posttraumatic endophthalmitis cases), and three unknown type of injuries. Six of the seven patients with an intraocular tumor received radiation, and in only three of those cases, the prosthesis could be successfully worn. 
Table I Indications of enucleation/evisceration before the dermisfat graft

\begin{tabular}{ll}
\hline Indications of enucleation/evisceration & No of patients \\
\hline Trauma & $\mathrm{II}$ \\
Corneal ulcer & 8 \\
Intraocular tumors & 7 \\
Congenital anomalies of eye & 3 \\
Thermal burn & 2 \\
Congenital glaucoma & 2 \\
Endophthalmitis & 2 \\
Painful blind eye & 2 \\
Unknown causes & 2 \\
Chemical burn & 1 \\
Necrotizing scleritis & 1 \\
\hline
\end{tabular}

Enucleation with a primary dermis-fat graft was performed in six patients - one suffered a blast injury, one a chemical burn, one a severe corneal ulcer with scleral melting, one advanced glaucoma with multiple surgeries, one necrotizing scleritis, and the last one had an unknown cause. Twenty-four patients underwent enucleation and 11 others evisceration. There were various types of orbital implants employed in this study: 24 nonporous and eight porous, and three patients received no orbital implant. Before the secondary dermis-fat graft, 32 of the 35 patients involved underwent enucleation/evisceration by nonoculoplastic surgeons.

Thirty patients received a dermis-fat graft alone, and 22 of them were able to wear their eye prosthesis. Four patients underwent a combined procedure (dermis-fat graft and fornix reconstruction using a mucous membrane or hard-palate graft). Of those, only one patient could wear the eye prosthesis and two others underwent fornix reconstruction subsequently and were able to wear their eye prosthesis. Moreover, seven patients had a dermis-fat graft with adding fornix reconstruction; five of them could wear their eye prosthesis and one patient could wear the conformer. With regard to the primary dermis-fat graft cases, $50 \%$ of them could wear the eye prosthesis. Finally, 30 of our total patients were able to wear their eye prosthesis and 29 of those accepted it cosmetically (Figures 1 and 2). Six patients were on a conformer because four of them experienced chronic discharge and the other two did not present to the hospital to have their eye prosthesis made, and the other five could wear neither the eye prosthesis nor the conformer because of severe socket contraction.

\section{Discussion}

In 1978, the dermis-fat graft for anophthalmic socket reconstruction was introduced by Smith et al. ${ }^{18}$ Since then, it has been used both primarily, after enucleation, and secondarily, after the extrusion or migration of an existing implant. ${ }^{18-21}$

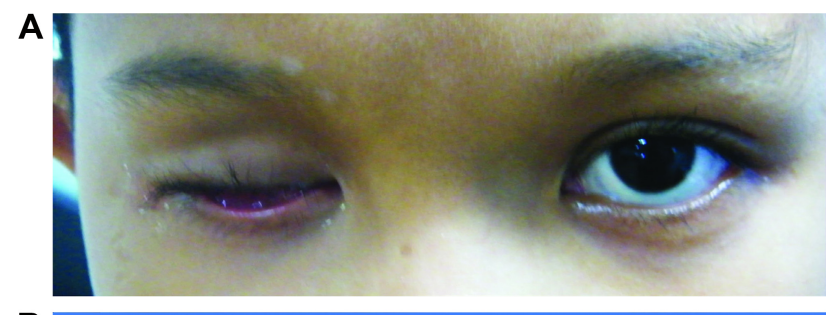

B
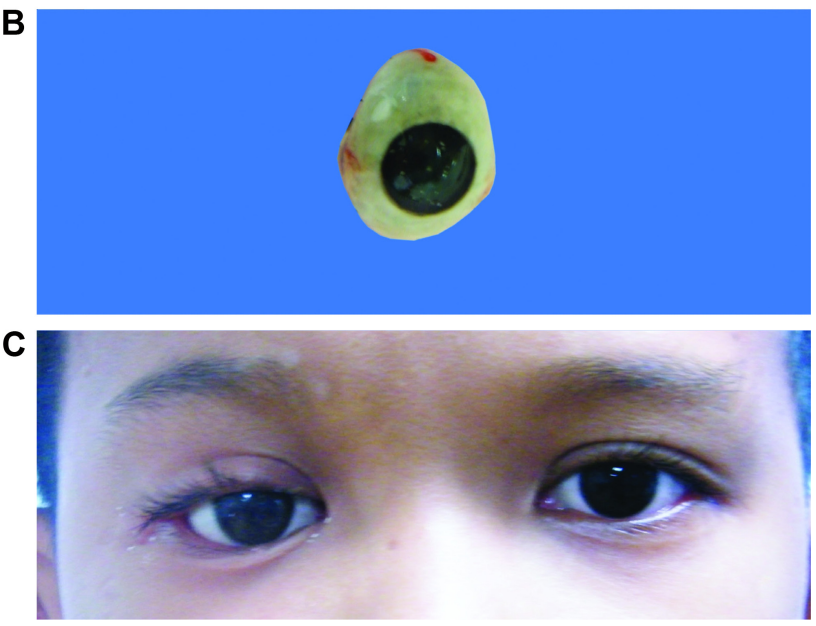

Figure I (A) Before the eye prosthesis wearing, a boy who underwent evisceration with no orbital implant when he was 3 months old. He could not wear the eye prosthesis because of volume insufficiency and shallow fornice. After that he underwent the dermis-fat graft with lateral tarsal strip procedure when he was 3 years old. (B) The custom-made eye prosthesis. (C) After the eye prosthesis wearing at 6-year-postoperative dermis-fat graft.
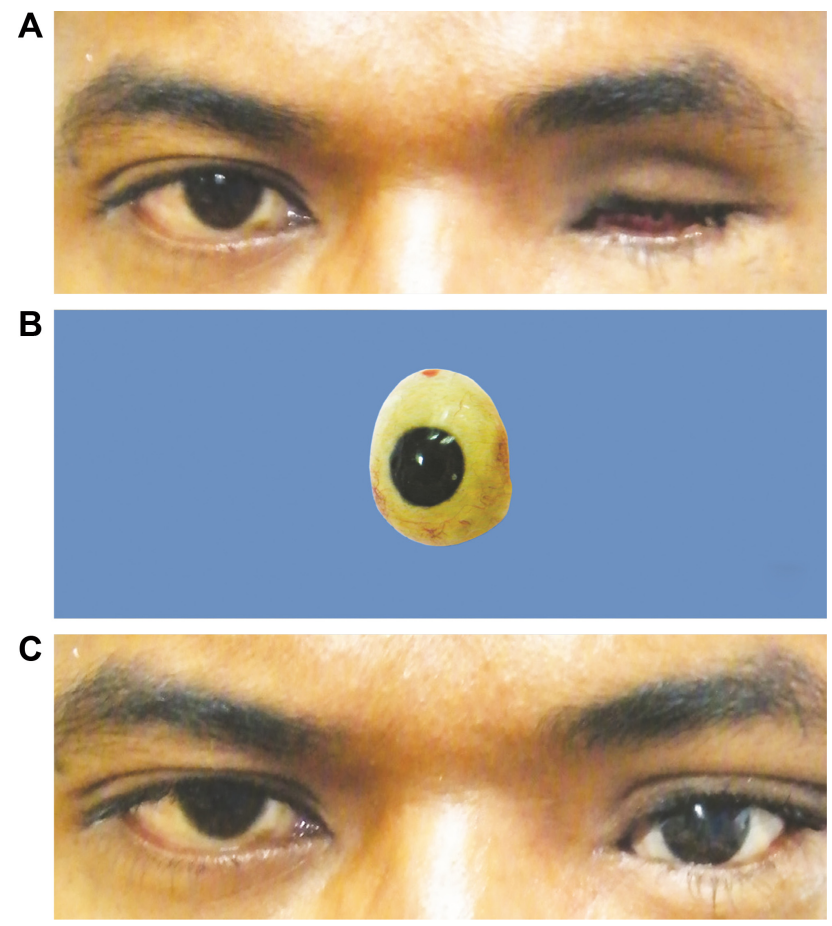

Figure 2 (A) Before the eye prosthesis wearing, a 25-year-old male who underwent evisceration with nonporous implant. He could not wear the eye prosthesis because of volume insufficiency. After that he underwent the secondary dermis-fat graft. (B) The custom-made eye prosthesis. (C) After the eye prosthesis wearing at 2.8-year-postoperative dermis-fat graft. 
Smith et al have proposed that the advantage of the dermis-fat graft lies in its ability to replace the orbital volume, while, at the same time, maintaining the fornix and conjunctiva. ${ }^{19}$ Therefore, it has been accepted as a technique to reconstruct the anophthalmic socket because this procedure is more preferable in the case of implant extrusion, large exposure, as well as volume insufficiency with a shallow fornix.

Our study showed three major indications for a secondary dermis-fat graft - exposure (13/41), extrusion (11/41), and volume insufficiency with a shallow fornix (10/41) which accounted for $82.9 \%$ of our total cases. A $4.5 \%-9.6 \%$ implant-exposure rate for porous orbital implants has been reported, depending on the type of material. ${ }^{20-22}$ Autogenous dermis-fat grafts implanted within the orbit survive the best, with little loss of volume, when they are placed within Tenon's capsule immediately following the removal of the globe and when the rectus muscles (and anterior ciliary arteries) are anastomosed to the dermal edge of the graft. ${ }^{23}$ The primary dermis-fat graft in young children's orbits appears to grow after implantation, which lends for a superior result for the primary procedure compared to the secondary one. ${ }^{7}$

We preferred to perform the dermis-fat graft in cases of implant exposure because many of our patients had concurrent infection. This procedure has been successful in overcoming some limitations of implant extrusion or exposure in procedures involving other materials. The autogenous dermis-fat graft is safe because it is characterized by no foreign-body reaction and disease transmission. ${ }^{24}$ Out of the six adult patients who underwent primary dermis-fat grafts, only $50 \%$ were successful. The success rate of a primary dermis-fat graft in our study was low because six patients had a severe conjunctival defect initially and a high risk for further socket retraction.

We preferred to perform a dermis-fat graft for implant extrusion because the average length of time before the secondary dermis-fat graft could be performed was 7.1 months, ie, it was a long enough period of time to introduce conjunctival shrinkage because our center is the only one in Southern Thailand to offer this procedure, and we experience long queues. The causes of enucleation/evisceration also pose a risk for conjunctival damage. The enucleation/evisceration was most of the time performed by nonoculoplastic surgeons (91.4\%), so the muscles and conjunctiva might not be preserved. Thirty of our subjects were able to wear the eye prosthesis. Five patients could not wear their eye prosthesis, with an inadequate fornix being the main factor. Although the dermis-fat graft can augment a volume-deficient socket and an insufficient fornix, nine of our patients underwent fornix reconstruction by a mucous membrane or a hard-palate graft. Initially, the surgeon performed the combined procedure, which was successful in $25 \%$ of cases, so the surgeon opted for a dermis-fat graft with an extended dermis to replace the superior and inferior fornix. The possible reason for the low success rate in the combined procedure may be insufficient blood supply from the base, which is a cause of mucous-membrane graft shrinkage.

The size of the dermis-fat graft harvested in our study was $30 \%$ larger than the defect measurement size because some fat has the potential for shrinkage and also because Smith et al reported a dermis-fat graft volume atrophy of more than $40 \%$ in three out of nine patients after the secondary procedure. ${ }^{19}$ On the other hand, a 5\%-10\% dermis-fat volume loss in the primary procedure has been reported. ${ }^{19,25}$ However, according to Sihota et al who compared the results between a $10-\mathrm{mm}$ and a $20-\mathrm{mm}$ thickness, the thicker the dermis-fat graft, the better the outcome. ${ }^{26}$

In conclusion, the dermis-fat graft has been used for anophthalmic socket reconstruction because it can replace the orbital volume, fornix, and conjunctiva. It is suitable as both a primary and secondary procedure, and is able to overcome the problems related to implant exposure and extrusion.

\section{Disclosure}

The authors report no conflicts of interest in this work.

\section{References}

1. Babar TF, Hussain M, Zaman M. Clinico-pathologic study of 70 enucleations. J Pak Med Assoc. 2009;59(9):612-614.

2. Custer PL, Trinkaus KM. Porous implant exposure: incidence, management, and morbidity. Ophthal Plast Reconstr Surg. 2007;23(1): $1-7$.

3. Lee BJ, Lewis CD, Perry JD. Exposed porous orbital implants treated with simultaneous secondary implant and dermis fat graft. Ophthal Plast Reconstr Surg. 2010;26(4):273-276.

4. Mallipatna AC, Sutherland JE, Gallie BL, Chan H, Héon E. Management and outcome of unilateral retinoblastoma. JAAPOS. 2009;13(6): 546-550.

5. Heher KL, Katowitz JA, Low JE. Unilateral dermis-fat graft implantation in the pediatric orbit. Ophthal Plast Reconstr Surg. 1998;14(2): $81-88$.

6. Mitchell KT, Hollsten DA, White WL, O'Hara MA. The autogenous dermis-fat orbital implant in children. J AAPOS. 2001;5(6):367-369.

7. Tarantini A, Hintschich C. Primary dermis-fat grafting in children. Orbit. 2008;27(5):363-369.

8. Lee MJ, Khwarg SI, Choung HK, Kim NJ, Yu YS. Dermis-fat graft for treatment of exposed porous polyethylene implants in pediatric postenucleation retinoblastoma patients. Am J Ophthalmol. 2011;152(2): 244-250.

9. Kim NJ, Choung HK, Khwarg SI, Yu YS. Free orbital fat graft to prevent porous polyethylene orbital implant exposure in patients with retinoblastoma. Ophthal Plast Reconstr Surg. 2005;21(4): 253-258.

10. Su GW, Yen MT. Current trends in managing the anophthalmic socket after primary enucleation and evisceration. Ophthal Plast Reconstr Surg. 2004;20(4):274-280. 
11. Viswanathan P, Sagoo MS, Olver JM. UK national survey of enucleation, evisceration and orbital implant trends. Br J Ophthalmol. 2007; 91(5):616-619.

12. Vagefi MR, McMullan TF, Burroughs JR, et al. Autologous dermis graft at the time of evisceration or enucleation. Br J Ophthalmol. 2007; 91(11):1528-1531.

13. Kim YD, Goldberg RA, Shorr N, Steinsapir KD. Management of exposed hydroxyapatite orbital implant. Ophthalmol. 1994;101(10): 1709-1715.

14. Rosen CE. The Müller muscle flap for repair of an exposed hydroxyapatite orbital implant. Ophthal Plast Reconstr Surg. 1998;14(3):204-207.

15. Soparkar CN, Patrinely JR. Tarsal patch-flap for orbital implant exposure. Ophthal Plast Reconstr Surg. 1998;14(6):391-397.

16. Salour H, Owji N, Farahi A. Two-stage procedure for management of large exposure defects of hydroxyapatite orbital implant. Eur J Ophthalmol. 2003;13(9-10):789-793.

17. Sami D, Young S, Petersen R. Perspective on orbital enucleation implants. Surv Ophthalmol. 2007;52(3):244-265.

18. Smith B, Petrelli R. Dermis-fat graft as a movable implant within the muscle cone. Amer J Ophthalmol. 1978;85(1):62-66.
19. Smith B, Bosniak S, Nesi F, Lisman R. Dermis-fat orbital implantation: 118 cases. Ophthalmic Surg. 1983;14(11):941-943.

20. Jordan DR, Klapper SR, Gilberg SM, Dutton JJ, Wong A, Mawn L. The bioceramic implant: evaluation of implant exposures in 419 implants. Ophthal Plast Reconstr Surg. 2010;26(2):80-82.

21. Jung SK, Cho WK, Paik JS, Yang SW. Long-term surgical outcomes of porous polyethylene orbital implants: a review of 314 cases. $\mathrm{BrJ}$ Ophthalmol. 2012;96(4):494-498.

22. Ramey N, Gupta D, Price K, Husain A, Richard M, Woodward J. Comparison of complication rates of porous anophthalmic orbital implants. Ophthalmic Surg Lasers Imaging. 2011;42(5):434-440.

23. Bosniak SL. Dermis-fat orbital implantation and complex socket deformities. Adv Ophthalmic Plast Reconstr Surg. 1992;9:131-141.

24. Nentwich MM, Schebitz-Walter K, Hirneiss C, Hintschich C. Dermis fat grafts as primary and secondary orbital implants. Orbit. 2014;33(1): 33-38.

25. Martin PA, Rogers PA, Billson F. Dermis-fat graft: evolution of a living prosthesis. Aust N Z J Ophthalmol. 1986;14(2):161-165.

26. Sihota R, Sujatha Y, Betharia SM. The fat pad in dermis fat grafts. Ophthalmology. 1994;101(2):231-234.
Clinical Ophthalmology

\section{Publish your work in this journal}

Clinical Ophthalmology is an international, peer-reviewed journa covering all subspecialties within ophthalmology. Key topics include: Optometry; Visual science; Pharmacology and drug therapy in eye diseases; Basic Sciences; Primary and Secondary eye care; Patien Safety and Quality of Care Improvements. This journal is indexed on

Submit your manuscript here: http://www.dovepress.com/clinical-ophthalmology-journal

\section{Dovepress}

PubMed Central and CAS, and is the official journal of The Society of Clinical Ophthalmology (SCO). The manuscript management system is completely online and includes a very quick and fair peer-review system, which is all easy to use. Visit http://www.dovepress.com/ testimonials.php to read real quotes from published authors. 